\title{
Statin use is associated with a lower risk of recurrence after curative resection in BCLC stage 0-A hepatocellular carcinoma
}

Shih-Yu Yang ${ }^{1}$, Chih-Chi Wang ${ }^{2}$, Kuang-Den Chen ${ }^{3}$, Yueh-Wei Liư, Chih-Che Lin², Ching-Hui Chuang ${ }^{4}$, Yu-Chieh Tsai ${ }^{1}$, Chih-Chien Yao ${ }^{1}$, Yi-Hao Yen ${ }^{1}$, Chang-Chun Hsiao ${ }^{5,6}$, Tsung-Hui Hu ${ }^{1}$ and Ming-Chao Tsai ${ }^{1,5^{*}}$ (i)

\begin{abstract}
Background: Use of statins is associated with a reduced risk of hepatocellular carcinoma (HCC). However, the effect of statin use on HCC recurrence is unclear. This study aimed to evaluate the effect of statin use on recurrence after curative resection among patients with HCC.

Methods: We retrospectively assessed 820 patients with Barcelona Clinic Liver Cancer (BCLC) stage 0 or A HCC who underwent primary resection between January 2001 and June 2016 at Kaohsiung Chang Gung Memorial Hospital. Exposure to statins was defined as use of a statin for at least 3 months before HCC recurrence. Factors that influenced overall survival (OS) and recurrence-free survival (RFS) were analyzed using Cox proportional hazards models.

Results: Of the 820 patients, 46 (5.6\%) used statins (statin group) and 774 (94.4\%) did not (non-statin group). During the mean follow-up of 76.5 months, 440 (53.7\%) patients experienced recurrence and 146 (17.8\%) patients died. The cumulative incidence of HCC recurrence was significantly lower in the statin group than the non-statin group ( $p=0.001$ ); OS was not significantly different between groups. In multivariate analysis, age (hazard ratio [HR]: 1.291; $p=0.010$ ), liver cirrhosis (HR: 1.743; $p<0.001$ ), diabetes (HR:1.418; $p=0.001$ ), number of tumors (HR: 1.750; $p<0.001$ ), tumor size (HR: 1.406; $p=0.004)$ and vascular invasion (HR: 1.659; $p<0.001$ ) were independent risk factors for HCC recurrence, whereas statin use (HR: 0.354; $p<0.001$ ) and antiviral therapy (HR: 0.613; $p<0.001$ ) significantly reduced the risk of HCC recurrence. The statin group still had lower RFS than the non-statin group after one-to-four propensity score matching.
\end{abstract}

Conclusion: Statins may exert a chemo-preventive effect on HCC recurrence after curative resection.

Keywords: Hepatocellular carcinoma, Statin, Resection, Recurrence

\footnotetext{
* Correspondence: tony0779@gmail.com

'Division of Hepato-Gastroenterology, Department of Internal Medicine,

Kaohsiung Chang Gung Memorial Hospital and Chang Gung University College of Medicine, 123 Ta Pei Road, Kaohsiung, Taiwan

${ }^{5}$ Graduate Institute of Clinical Medical Sciences, College of Medicine, Chang Gung University, Taoyuan, Taiwan

Full list of author information is available at the end of the article
}

(c) The Author(s). 2021 Open Access This article is licensed under a Creative Commons Attribution 4.0 International License, which permits use, sharing, adaptation, distribution and reproduction in any medium or format, as long as you give appropriate credit to the original author(s) and the source, provide a link to the Creative Commons licence, and indicate if changes were made. The images or other third party material in this article are included in the article's Creative Commons licence, unless indicated otherwise in a credit line to the material. If material is not included in the article's Creative Commons licence and your intended use is not permitted by statutory regulation or exceeds the permitted use, you will need to obtain permission directly from the copyright holder. To view a copy of this licence, visit http://creativecommons.org/licenses/by/4.0/ The Creative Commons Public Domain Dedication waiver (http://creativecommons.org/publicdomain/zero/1.0/) applies to the data made available in this article, unless otherwise stated in a credit line to the data. 


\section{Background}

Hepatocellular carcinoma (HCC), the most common primary malignancy of the liver, is the second leading cause of cancer-related deaths in many regions of the world [1]. Approximately 850,000 new cases of HCC are diagnosed worldwide per year [2]. The main risk factors for $\mathrm{HCC}$ are chronic infection with hepatitis $\mathrm{B}$ virus $(\mathrm{HBV})$ or hepatitis $\mathrm{C}$ virus $(\mathrm{HCV})$, consumption of aflatoxin-contaminated foodstuffs, heavy alcohol intake, obesity, smoking and type 2 diabetes [3]. The current management strategies for HCC depend on the tumor stage and include surgical resection, liver transplantation, radiofrequency ablation (RFA), transarterial chemoembolization, radiation therapy and systemic therapy $[4,5]$. The ideal candidates for resection are patients with early stage (BCLC stage 0 or A) who do not have extrahepatic metastasis, macrovascular invasion or clinically significant portal hypertension [6].

Surgical resection is a potentially curative treatment for $\mathrm{HCC}$, though cumulative recurrence rates remain high (50-60\%) [7-10]. Known risk factors for HCC recurrence after hepatectomy are tumor size, serum $\alpha$ fetoprotein, tumor differentiation, microvascular invasion, cirrhosis, surgical margin, serum HBV viral load and metabolic syndrome [7, 9, 11-13]. Nucleos(t)ide analogue (NA) therapy may reduce the risk of HCC recurrence after hepatic resection among patients with HBV-related HCC [14]. The adjuvant therapy sorafenib, a targeted therapy for advanced $\mathrm{HCC}$, has been proven not to prevent $\mathrm{HCC}$ recurrence after complete resection or ablation of primary HCC [15]. However, using NA therapy alone is not enough to prevent $\mathrm{HCC}$ recurrence. To decrease the risk of HCC recurrence after curative resection, other effective chemopreventive agents need to be identified.

Statins, cholesterol-lowering 3-hydroxy-3-methyglutaryl-coenzyme A (HMG-CoA) reductase inhibitors, are the most common medications used for primary and secondary prevention of cardiovascular disease and mortality [16]. In addition to their effect on cholesterol biosynthesis, numerous previous studies have indicated statins can exert chemopreventive effects and reduce the risk of $\mathrm{HCC}$ in individuals with $\mathrm{HBV}$ $[17,18]$ or $\operatorname{HCV}[19,20]$ infection. In vitro studies and animal models have explored the mechanisms underlying the anticancer effects of statins in HCC $[21,22]$. Although these studies demonstrate statins reduce the risk of developing $\mathrm{HCC}$, few studies have explored the impact of statins on the outcome of patients with HCC after curative resection. Thus, we aimed to evaluate the effect of statin use on the risk of recurrence after curative resection in patients with HCC.

\section{Methods}

Study design

The data used in this study were extracted from the Kaohsiung Chang Gung Memorial Hospital HCC registry database. A total of 2137 patients diagnosed with HCC who underwent surgical resection between January 2001 and June 2016 at Kaohsiung Chang Gung Memorial Hospital were retrospectively enrolled. We excluded 918 patients with Barcelona Clinic Liver Cancer (BCLC) stage $\mathrm{B}$ or $\mathrm{C}, 234$ patients who underwent prior treatment for HCC and 67 patients who developed recurrence within less than 3 months after resection. In well-selected patients, liver transplantation is generally considered to cure the tumor and underlying cirrhosis at the same time, thus strongly influences survival and recurrence [23]. Therefore, 98 patients who underwent salvage liver transplantation were also excluded. Finally, a total of 820 patients with BCLC stage 0 or A HCC who underwent primary curative resection (Fig. 1) were included in this study.

This study was conducted in accordance with the standards of the Declaration of Helsinki and current ethics guidelines; approval was obtained from the Ethics Committee of Chang Gung Memorial Hospital (IRB number: 201901103B0). The requirement for informed consent was waived by the IRB; all data were analyzed anonymously.

\section{Exposure to chemopreventive agents}

To define the statins group and non-statins group, we calculated the defined daily dose (DDD) recommended by the World Health Organization to measure the amount of drugs prescribed [24]. Cumulative DDD (cDDD) was estimated as the sum of the dispensed DDDs for any statin (namely Atorvastatin, Fluvastatin, Pitavastatin and Rosuvastatin) before HCC recurrence. Patients taking a statin CDDD of more than 90 were enrolled in the statins group; patients with statin CDDD of less than 90 were enrolled in the non-statins group. The cDDD for other chemopreventive agents including aspirin, NSAIDs (namely diclofenac, ibuprofen, indomethacin, mefenamic acid, aceclofenac, sulindac, celecoxib, etoricoxib and naproxen), and metformin were also recorded.

\section{Study assessments and follow-up evaluation}

Medical records were reviewed to obtain data on patient demographics and clinical characteristics, including serum biochemistry, albumin, alpha-fetoprotein (AFP), Child-Pugh classification, viral hepatitis status, duration of follow-up and outcomes. The diagnosis of cirrhosis was confirmed using the histopathology reports for surgically resected non-tumor tissues. HCC stage was defined according to the BCLC guidelines [25]. Tumor 


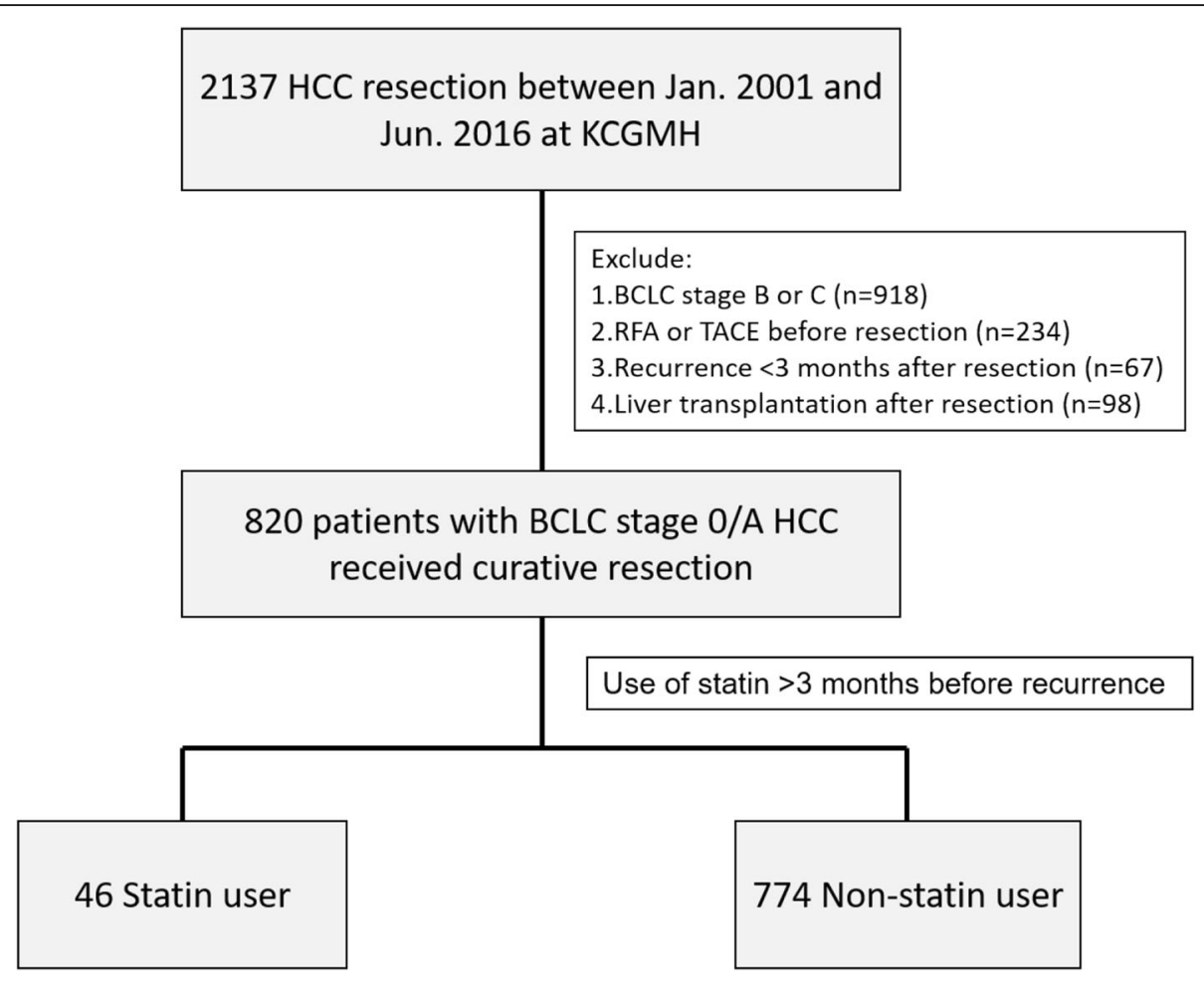

Fig. 1 Patient selection flow diagram

differentiation was assessed using the Edmondson grading system.

Patients were followed-up 1 month after surgery, every 3 months in the first year, and every 3-6 months in subsequent years. Serum AFP levels, serum biochemistry and abdominal ultrasonography were performed at every follow-up. Dynamic computed tomography or magnetic resonance studies were performed 1 month after resection and every 12 months thereafter, or if HCC recurrence was clinically suspected. Last follow-up was April 30, 2020. Recurrence-free survival (RFS) was defined as the interval between surgery and the date of diagnosis of the first recurrence; overall survival (OS), as the interval between surgery and death or last follow-up.

\section{Statistical analysis}

Propensity score matching (PSM) was applied to reduce selection bias between the study groups. Age, sex, diabetes mellitus, hepatitis $\mathrm{B}$, hepatitis $\mathrm{C}$, liver cirrhosis, Child-Pugh grade, tumor size, tumor number and microvascular invasion were selected as independent variables. The greedy method of NCSS 10 Statistical Software (LLC, Kaysville, UT, USA) was used for matching the study groups in a 1:4 ratio; the caliper width was 0.2 of the standard deviation of the propensity score between study groups. The standardized mean difference
(SMD) was used to evaluate covariate balance after PSM.

Demographic data were compared between groups using Fisher's exact test or the chi-square test, as appropriate. Continuous variables are expressed as the median \pm interquartile range (IQR). The Kaplan-Meier method was used to plot the RFS and OS curves stratified by chemopreventive agent use and the curves were compared using the log-rank test. Factors that were significant in the univariate analysis $(p<0.05)$ were included in multivariate analyses of OS and RFS using a Cox forward stepwise variable selection process. Hazard ratios (HR) and 95\% confidence intervals (CI) were also calculated for each factor. Statistical analyses were performed using SPSS 22.0 software (SPSS Inc., Chicago, IL, USA). All statistical tests were two-sided; $p$-values $<0.05$ were considered significant.

\section{Results}

Comparison of the clinical characteristics of patients with and without statin use

Table 1 summarizes the characteristics of the study cohort, which included 639 males and 181 females, with an age range of 52-66-years-old and median age of 59 . Overall, 222 patients (27.1\%) had diabetes before surgery and 378 (46.1\%) were diagnosed with cirrhosis. Cirrhosis was defined as METAVIR stage 4 fibrosis based on 
Table 1 Comparison of clinical and pathological characteristics before hepatectomy for patients with or without statin use

\begin{tabular}{|c|c|c|c|c|}
\hline & Total $(n=820)$ & Statin $(n=46)$ & Non-statin $(n=774)$ & $P$-value \\
\hline Age (years; median, IQR) & $58.8(52-66)$ & $62(58-63)$ & $58.6(52-66)$ & 0.037 \\
\hline Age (> 60 years), $n(\%)$ & $432(52.7 \%)$ & $31(67.4 \%)$ & $401(51.8 \%)$ & 0.04 \\
\hline Male, $n(\%)$ & $639(77.9 \%)$ & $40(87.0 \%)$ & $599(77.4 \%)$ & 0.129 \\
\hline Bilirubin (g/dL; median, IQR) & $0.8(0.6-1.0)$ & $0.8(0.5-1.0)$ & $0.8(0.6-1.0)$ & 0.556 \\
\hline Albumin (g/dL; median, IQR) & $3.7(3.2-4.1)$ & $3.8(3.5-4.2)$ & $3.6(3.2-4.1)$ & 0.129 \\
\hline $\operatorname{AFP}(>200 \mathrm{ng} / \mathrm{mL}), n(\%)$ & 145 (18.2\%) & $6(14.6 \%)$ & 139 (18.4\%) & 0.547 \\
\hline Liver cirrhosis, $n$ (\%) & $378(46.1 \%)$ & $12(26.1 \%)$ & $366(47.3 \%)$ & 0.005 \\
\hline Hepatitis B, n (\%) & $458(55.9 \%)$ & $22(47.8 \%)$ & $436(56.3 \%)$ & 0.259 \\
\hline Hepatitis C, n (\%) & $284(34.6 \%)$ & $14(30.4 \%)$ & $270(34.9 \%)$ & 0.538 \\
\hline Diabetes, $n(\%)$ & $214(26.1 \%)$ & $27(58.7 \%)$ & $187(24.2 \%)$ & $<0.001$ \\
\hline Tumor size (> $2 \mathrm{~cm}), n(\%)$ & $614(74.9 \%)$ & $42(91.3 \%)$ & $572(73.9 \%)$ & 0.008 \\
\hline Tumor number (single:multiple) & $750: 70$ & $44: 2$ & $706: 68$ & 0.296 \\
\hline Child-Pugh grade (A:B) & $752: 68$ & $42: 4$ & $710: 64$ & 0.919 \\
\hline Microvascular invasion, $n$ (\%) & $302(36.8 \%)$ & $22(47.8 \%)$ & $280(36.2 \%)$ & 0.112 \\
\hline Histological grade (well:moderate:poor) & 107:684:19 & $6: 38: 1$ & 101:646:18 & 0.965 \\
\hline Recurrence, $n(\%)$ & $440(53.7 \%)$ & $15(32.6 \%)$ & 425 (54.9\%) & 0.003 \\
\hline Death, $n(\%)$ & $146(17.8 \%)$ & $7(15.2 \%)$ & 139 (18.0\%) & 0.637 \\
\hline
\end{tabular}

AFP a-fetoprotein

histopathological evaluation of resected non-tumor liver tissues [26].

Of the 820 patients, $46(5.6 \%)$ were taking statins (statin group) and 774 (94.4\%) were not taking statins (non-statin group). Compared to the non-statin group, the patients in the statin group were significantly older ( $p=0.037)$ and had a higher frequency of diabetes mellitus (DM; $p<0.001)$ and larger tumors $(p=0.008)$, but a lower frequency of cirrhosis $(p=0.005)$. Overall, the statin group had a lower rate of recurrence $(p=0.003)$, though overall survival was not significant different between the statin and non-statin groups $(p=0.667)$.

\section{Factors associated with HCC recurrence}

A total of 440 (53.7\%) patients developed recurrence during the mean follow-up period of 76.5 months. The Kaplan-Meier curves shown in Fig. 2 indicated statin use $(p=0.001)$ was associated with a significantly lower risk of HCC recurrence. In contrast, aspirin, NSAIDs and metformin were not significantly associated with HCC recurrence. In subgroup analysis based on various clinical characteristics (Fig. 3), RFS was significantly higher in the statin group than non-statin group in the subgroups of patients with BCLC stage A $(p=0.001)$, $\mathrm{AFP}<200 \mathrm{ng} / \mathrm{mL} \quad(p=0.004)$, without cirrhosis ( $p=$ $0.02)$, CHB $(p=0.051)$, without DM $(p=0.018)$ and with $\mathrm{DM}(p=0.001)$.

In the stepwise Cox proportional hazard model (Table 2), age (HR:1.291; CI: 1.064-1.566; $p=0.010$ ), liver cirrhosis (HR: 1.743; CI: 1.437-2.113; $p<0.001$ ), diabetes
(HR:1.418; CI: $1.147-1.755 ; p=0.001$ ), multiple tumors (HR: 1.750; CI: 1.304-2.348; $p<0.001$ ), tumor size $>2$ cm (HR: 1.406; CI: $1.113-1.774 ; p=0.004)$ and vascular invasion (HR: 1.659; CI: 1.364-2.018; $p<0.001$ ) were independent risk factors for HCC recurrence. Moreover, statin use (HR: 0.354; CI: $0.210-0.599 ; p<0.001$ ) and antiviral therapy (HR: 0.613 ; CI: $0.503-0.748 ; p<0.001$ ) were associated with a significantly lower risk of HCC recurrence.

We further analyzed RFS in subgroup among $\mathrm{CHB}$ and $\mathrm{CHC}$ patients. Among $\mathrm{CHB}$ patients $(n=458)$, liver cirrhosis, diabetes, tumor number, tumor size and vascular invasion were independent risk factors for $\mathrm{HCC}$ recurrence. Statin and nucleos(t)ide analogues (NA) therapy were found to decrease HCC recurrence. Among $\mathrm{CHC}$ patients $(n=284)$, liver cirrhosis, tumor number and vascular invasion were significantly associated with HCC recurrence. HCV therapy was associated with a significantly lower risk of recurrence.

\section{Factors associated with overall survival}

A total of 146 (17.8\%) patients died during follow-up. Overall, 91 (62.3\%) patients died of liver-related causes: 82 of HCC and nine of complications associated with cirrhosis. Of the 55 patients who died of non-liverrelated causes, 36 died of sepsis, 10 of malignancies other than HCC, three of out-of-hospital cardiac arrest, three of heart failure, one of intracranial hemorrhage, one of in-hospital cardiac arrest and one of acute respiratory distress syndrome. The Kaplan-Meier curves in 


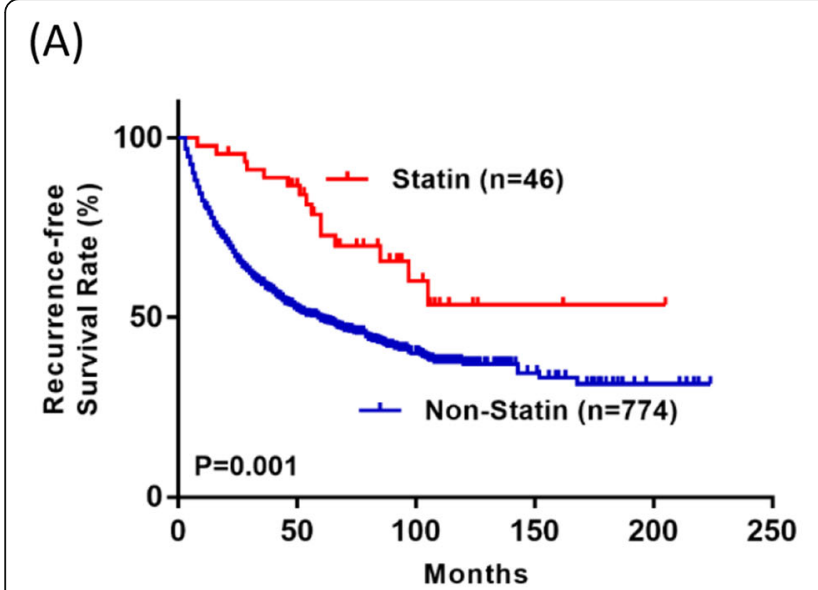

(B)

(C)

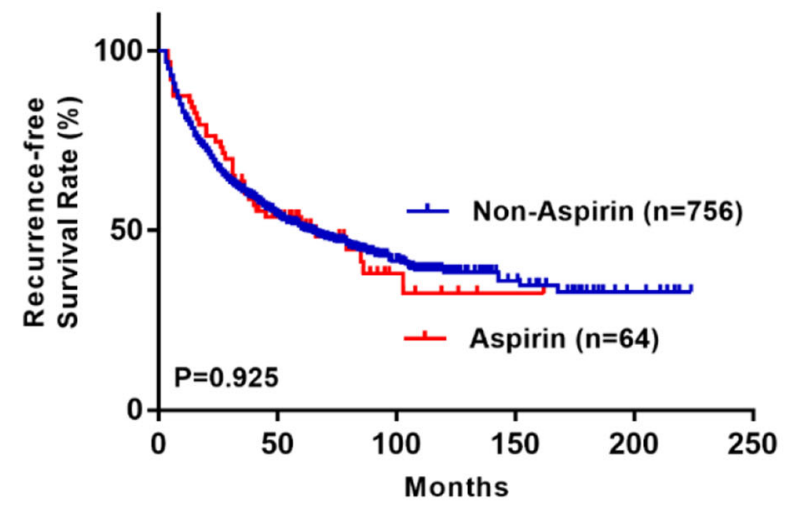

(D)
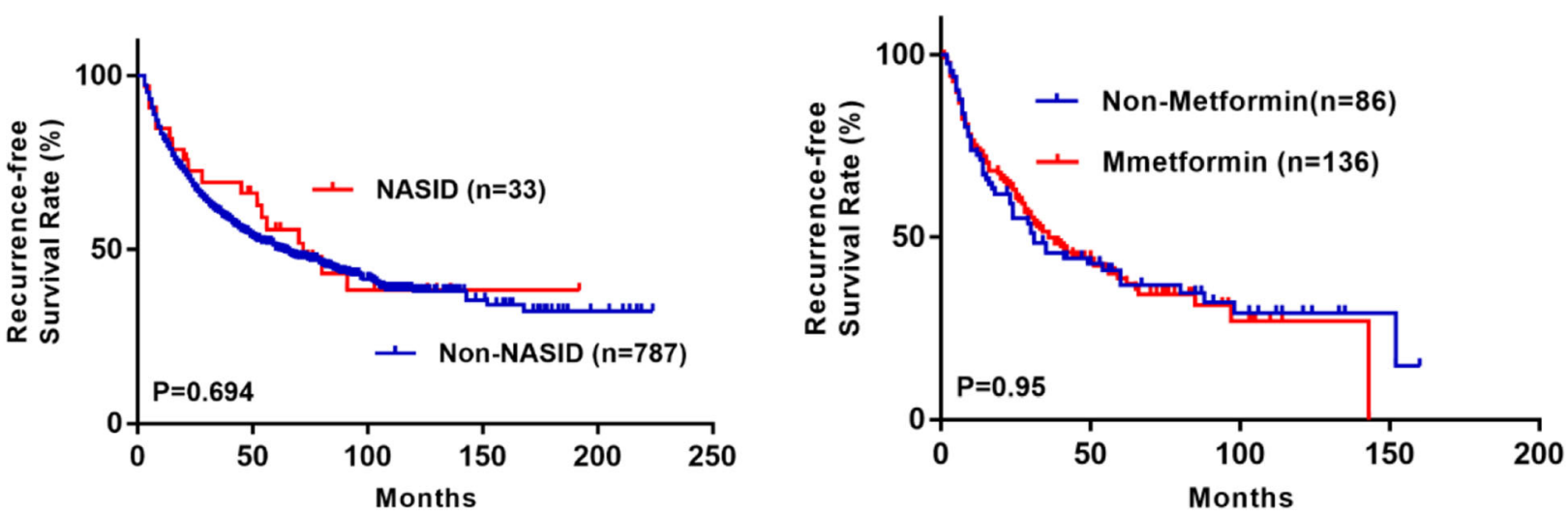

Fig. 2 Kaplan-Meier cumulative recurrence-free survival curves for patients stratified by a statin use, $\mathbf{b}$ aspirin use, c NSAID use and $\mathbf{d}$ metformin use

Fig. 4 suggested that statin, aspirin, NSAID and metformin use were not associated with OS.

In the stepwise Cox proportional hazard model (Table 3 ), liver cirrhosis (HR: 1.644; CI: 1.180-2.290; $p=0.003$ ), diabetes (HR: 2.064; CI: 1.478-2.881; $p<0.001$ ), ChildPugh grade (HR: 1.915; CI: 1.185-3.096; $p=0.008$ ) and vascular invasion (HR: 2.339; CI: $1.670-3.276 ; p<0.001$ ) were related to poorer OS, whereas antiviral therapy (HR: 0.350; CI: 0.241-0.509; $\mathrm{p}<0.001$ ) were associated with better OS.

In subgroup analysis, DM, Child-Pugh grade and vascular invasion were significantly associated with poor OS among $\mathrm{CHB}$ patients. Whereas, NA therapy was related to better OS. Among $\mathrm{CHC}$ patients, liver cirrhosis, diabetes and vascular invasion were related to poor OS, while HCV therapy was associated with better OS.

\section{Patient RFS and OS evaluation using propensity score- matching analysis}

After 1:4 case propensity score matching, 46 patients in the stain group and 174 patients in the non-statin group were analyzed. The baseline characteristics were balanced between the matched groups (SMD $<0.2$ and $p>$ 0.05 for all variables). The patient characteristics before and after matching are presented in Table 4. The RFS rate was significantly higher in the statin than non-statin group ( $p<0.001$, Fig. 5a). Moreover, statin use remained significantly associated with a reduced risk of HCC recurrence after PSM (HR: 0.328; CI: 0.190-0.566; $p<$ 0.001 ; Table 5 ). The OS rate was not significantly different between the groups after PSM (Fig. 5b and Table 6).

\section{Discussion}

Liver resection remains the mainstay of curative treatment for early-stage HCC with preserved liver function; however, the 5-year cumulative recurrence rates after resection are higher than 50\% [9]. Certain medications, including statins, aspirin, NSAIDs and metformin, have been reported to alter the risk of developing HCC [14, 17, 26-28]. However, the effects of these medications on HCC recurrence have not yet been examined. In this population-based, propensity score-matched study, we 
(A) BCLC stage
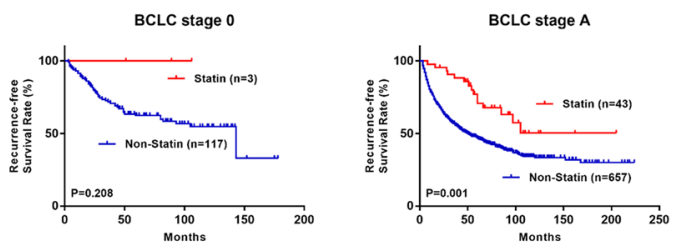

(B) Liver cirrhosis
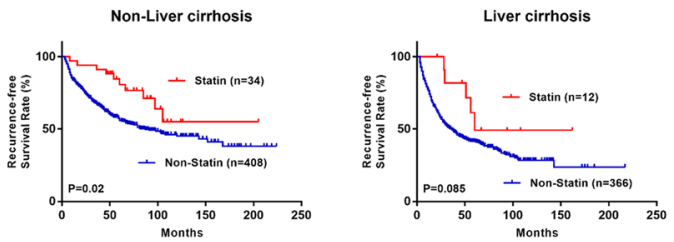

(C) Hepatitis

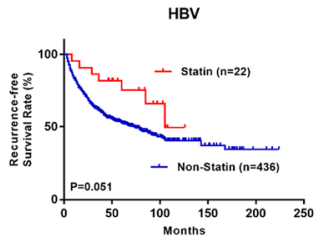

$\mathrm{HBV}+\mathrm{HCV}$

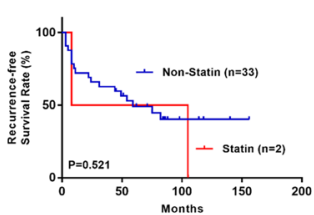

(D) AFP

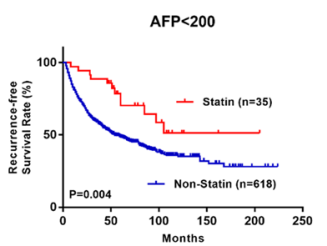

(E) DM

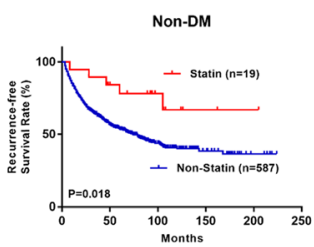

(F) Microvascular invasion

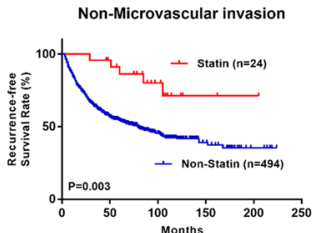

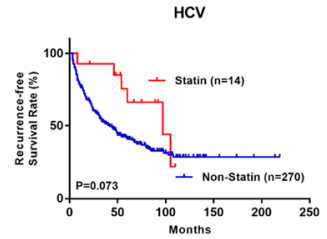
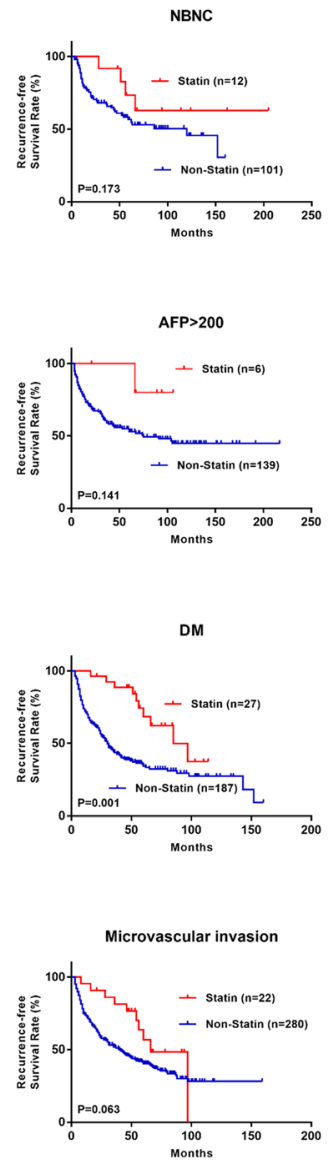

Fig. 3 Kaplan-Meier cumulative recurrence-free survival curves for patients with or without statin use stratified by $\mathbf{a}$ BCLC stage, $\mathbf{b}$ liver cirrhosis, $\mathbf{c}$ hepatitis, $\mathbf{d}$ serum AFP, e diabetes mellitus and $\mathbf{f}$ microvascular invasion

confirmed that statin use may lower the risk of $\mathrm{HCC}$ recurrence in patients with $\mathrm{HCC}$ after curative resection. This association remained consistent regardless of age, sex, cause of hepatitis, diabetic status or the presence or absence of cirrhosis, which suggests statins could be beneficially employed as a chemopreventive agent to reduce the risk of recurrence after resection in patients with HCC. These results emphasize the need for largescale RCTs to validate the potential chemopreventive effect of statins on the recurrence of HCC.

Statins, 3-hydroxy-3-methylglutaryl coenzyme A (HMG-CoA) reductase inhibitors, are used worldwide as a treatment for dyslipidemia and can prevent cardiovascular events and mortality [16, 29]. In addition to their cholesterol-lowering capability, increasing evidence indicates statins also exert anti-oncogenic effects. Kim et al. reported that statin use decreased the risk of developing HCC among patients with new-onset type 2 diabetes mellitus in a nested case-control, longitudinal study [30]. Tsan et al. demonstrated that statins may dosedependently reduce the risk of HCC among individuals with HBV or HCV infection $[17,19]$. Furthermore, a recent meta-analysis of 25 studies that included 1,925,964 patients concluded statins exert a beneficial chemopreventive effect against the development of HCC [31].

However, most of these studies focused on the ability of statins to protect against the development of HCC; only a few studies have assessed the potential of statins to protect against recurrence after curative resection. A retrospective study in Japan by Kawaguchi et al. showed that statins may protect against HCC recurrence [32]. Similarly, we found statin use was associated with a significantly lower risk of recurrence after resection (HR: $0.34 ; p=0.005$ ). However, OS, including liver- and nonliver-related mortality, were not significantly different between the statin and non-statin groups in this study (Supplementary Figure 2). The differences between the study by Kawaguchi et al. and our findings may be related to the varied proportions of patients with HBV and $\mathrm{HCV}$ infection. In the study by Kawaguchi et al., significantly fewer patients in the statin group had hepatitis B surface antigen (HBsAg) positivity and hepatitis $\mathrm{C}$ virus antibody (HCVAb) positivity compared to the non-statin group (HBsAg: $6.5 \%$ vs. $22.8 \%, p=0.032$; HCVAb: $19.4 \%$ vs. $45.0 \%, p=0.005)$. In the present study, there was no difference in the proportions of HBV- and HCV-positive patients between the statin and non-statin groups. More importantly, we also compared various potential chemopreventive agents, including statins, aspirin, metformin 
Table 2 Multivariate analysis of recurrence after curative hepatectomy for patients with BCLC O/A stage HCC

\begin{tabular}{|c|c|c|c|c|c|c|c|}
\hline \multirow[t]{2}{*}{ Variable } & \multirow[t]{2}{*}{ Comparison } & \multicolumn{2}{|l|}{ All $(n=820)$} & \multicolumn{2}{|l|}{$\mathrm{CHB}(n=458)$} & \multicolumn{2}{|l|}{$\mathrm{CHC}(n=284)$} \\
\hline & & HR $(95 \% \mathrm{Cl})$ & $P$-value & HR $(95 \% \mathrm{Cl})$ & $P$-value & HR $(95 \% \mathrm{Cl})$ & $P$-value \\
\hline Age (years) & $>60$ vs. $\leqq 60$ & $1.291(1.064-1.566)$ & 0.010 & & & & \\
\hline Sex & Male vs. Female & & & & & & \\
\hline $\operatorname{AFP}(\mathrm{ng} / \mathrm{mL})$ & $>200$ vs. $\leqq 200$ & & & & & & \\
\hline Liver cirrhosis & Yes vs. No & $1.743(1.437-2.113)$ & $<0.001$ & $1.991(1.530-2.592)$ & $<0.001$ & $1.617(1.187-2.203)$ & 0.002 \\
\hline Diabetes & Yes vs. No & $1.418(1.147-1.755)$ & 0.001 & $1.823(1.343-2.475)$ & $<0.001$ & & \\
\hline Child-Pugh grade & B vs. A & & & & & & \\
\hline Tumor number & Multiple vs. Single & $1.750(1.304-2.348)$ & $<0.001$ & $1.582(1.085-2.305)$ & 0.017 & $2.091(1.292-3.385)$ & 0.003 \\
\hline Tumor size (cm) & $>2$ vs. $\leqq 2$ & $1.406(1.113-1.774)$ & 0.004 & $1.716(1.221-2.411)$ & 0.002 & & \\
\hline Histology stages & Poor vs. well + moderate & & & & & & \\
\hline Vascular invasion & Yes vs. No & 1.659 (1.364-2.018) & $<0.001$ & $1.464(1.120-1.913)$ & 0.005 & 1.776 (1.309-2.409) & $<0.001$ \\
\hline Statin & Yes vs. No & $0.354(0.210-0.599)$ & $<0.001$ & $0.393(0.181-0.854)$ & 0.018 & & \\
\hline NSAIDs & Yes vs. No & & & & & & \\
\hline Aspirin & Yes vs. No & & & & & & \\
\hline Metformin & Yes vs. No & & & & & & \\
\hline Antiviral therapy & Yes vs. No & $0.613(0.503-0.748)$ & $<0.001$ & & & & \\
\hline NA therapy & Yes vs. No & & & $0.590(0.453-0.768)$ & $<0.001$ & & \\
\hline HCV therapy & Yes vs. No & & & & & $0.496(0.361-0.682)$ & $<0.001$ \\
\hline
\end{tabular}

NSAIDs Nonsteroidal anti-inflammatory drugs, NA therapy Nucleos(t)ide analogues

$\mathrm{HCV}$ therapy included interferon and direct-acting antiviral medications

and NSAIDs. To the best of our knowledge, this study represents the largest analysis of the relationship between chemopreventive agents and HCC recurrence in a country where HBV and HCV are endemic.

The mechanisms underlying the ability of statins to protect against HCC development are not well understood; some potential mechanisms have been suggested. First, statin-mediated reduction of downstream metabolites of the mevalonate pathway-including geranyl pyrophosphate, farnesyl pyrophosphate and geranylgeranyl pyrophosphate-interferes with cancer cell proliferation and differentiation, which promotes apoptosis [33, 34]. Secondly, statins can suppress proteasomal degradation, which limits breakdown of the cyclin-dependent kinase (CDK) inhibitors p21 and p27 and reduces CDK2 expression, and thus disrupts mitosis in malignant cells $[35,36]$. Third, statins may inhibit tumor cell migration and invasion by attenuating angiogenesis via downregulating VEGF production [37]. Fourth, statins exert antiinflammatory and immunomodulatory effects by decreasing TNF- $\alpha$ and IL- 6 expression, downregulating the activity of metalloproteinases, and inducing a shift towards the $\mathrm{TH} 2$ cytokine anti-inflammatory response, which may reduce hepatic inflammation [38, 39]. Chronic hepatic inflammation plays an important role in hepatocarcinogenesis [40]. Moreover, statins activate AMP-activated protein kinase, which enhances p21 expression and the endoplasmic reticulum stress response, and thus induces higher levels of autophagy [41].

Statins are generally classified into hydrophilic and lipophilic groups based on tissue selectivity. Lipophilic statins, including atorvastatin, simvastatin, lovastatin, fluvastatin and pitavastatin, distribute widely throughout various tissues. Hydrophilic statins, such as pravastatin and rosuvastatin, have lower levels of tissue absorption-except in the liver-and exert fewer side effects as they are not metabolized by cytochrome P450 enzymes [42]. Although a previous meta-analysis showed lipophilic statins, but not hydrophilic statins, were associated with a lower risk of developing HCC, we did not observe a significant difference in RFS between the subgroups of patients taking lipophilic and hydrophilic statins (Supplementary Figure 1). However, this analysis may be affected by the limited number of patients. Furthermore, the mechanisms that explain the varied anticancer efficacies of lipophilic and hydrophilic statins remain to be determined.

A recent cohort study by Young et al. indicated aspirin use-but, interestingly, not statin use-reduced the risk of HCC recurrence [43]. In contrast, aspirin use was not significantly associated with HCC recurrence in our cohort $(p=0.864)$. These discrepancies may be related to differences between the design of each study. Firstly, 


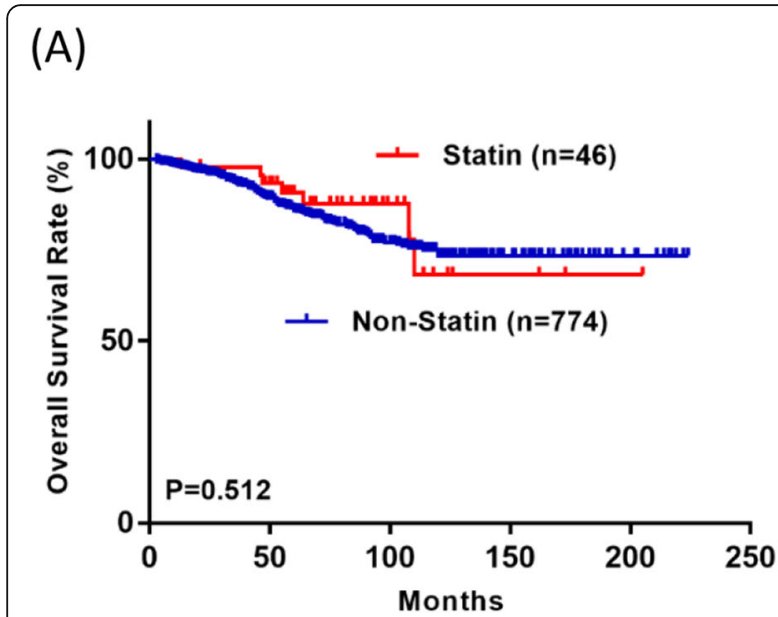

(C)

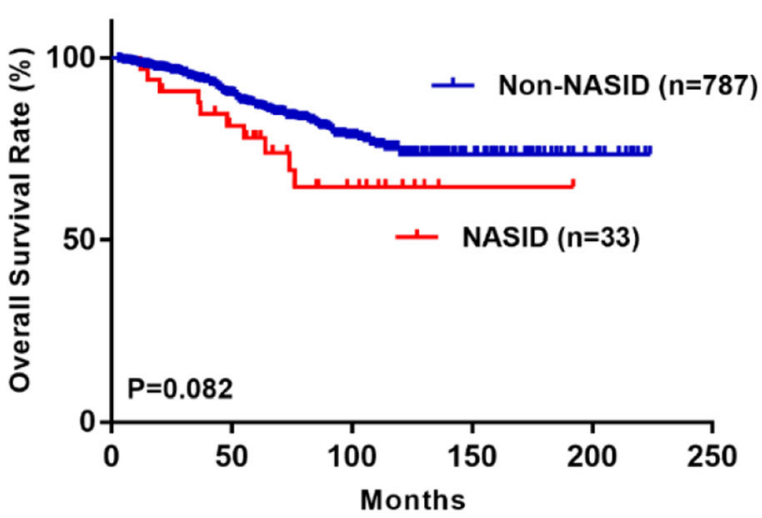

(B)

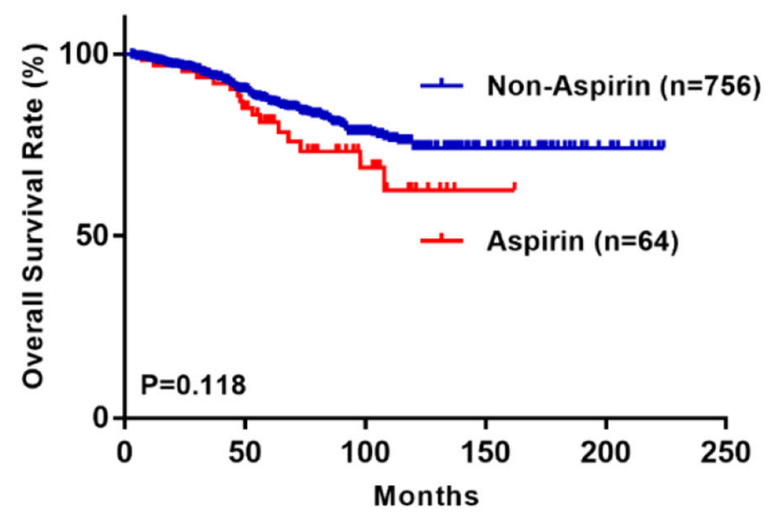

(D)

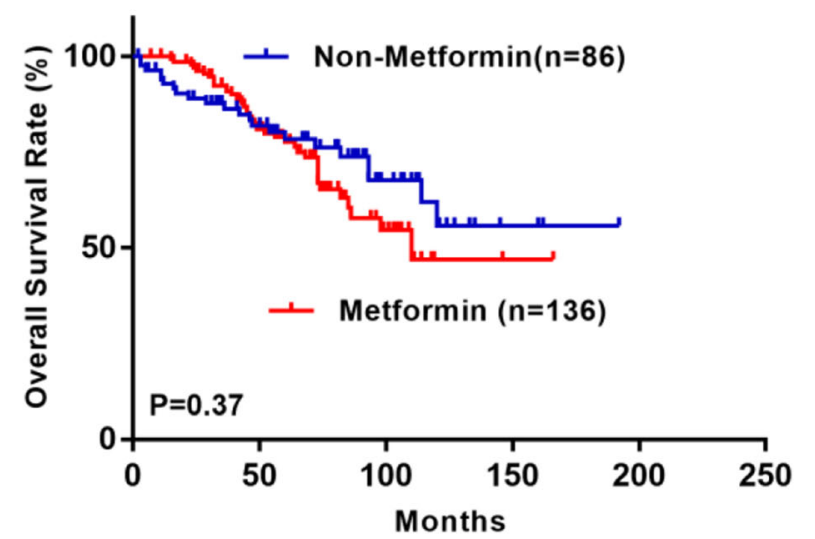

Fig. 4 Kaplan-Meier cumulative overall survival curves for patients stratified by a statin use, b aspirin use, c NSAID use and $\mathbf{d}$ metformin use

Young et al. only examined exposure to chemopreventive agents in the 30 days before tumor recurrence. However, we defined exposure as more than 90 days, as generally adopted by previous studies [32, 44]. Secondly, Young et al. enrolled patients with $\mathrm{BCLC}$ stage $\mathrm{A} / \mathrm{B} / \mathrm{C}$ $\mathrm{HCC}$ who underwent resection. In contrast, we only assessed patients with BCLC stage 0/A, so called earlystage $\mathrm{HCC}$, for which surgical resection is the widely accepted standard treatment. Moreover, Young et al. focused on HBV-related HCC, while we investigated all etiologies. Since no RCTs have been published in this field, our results further emphasize the need for largescale RCTs to validate the potential chemopreventive effect of statins on HCC recurrence.

We found that age, liver cirrhosis, diabetes, number of tumors, tumor size and vascular invasion represented the major risk factors for $\mathrm{HCC}$ recurrence, and antiviral therapy may reduce the risk of HCC recurrence. These results are consistent with previous reports $[7,9,11-14,45]$.
Increasing evidence indicates that gut microbiota alterations promote the development of HCC by inducing a leaky gut and gut dysbiosis; both of which are prominent features of all stages of chronic liver disease, and promote the stepwise progression from fibrosis to cirrhosis and HCC [46]. In addition to dysbiosis, gut microbiotaderived metabolites may also promote hepatocarcinogenesis via a variety of metabolic pathways [47]. Although there is no evidence to prove statin use affects HCC development and recurrence by altering the human gut microbiome, several studies have indicated statin therapy lowers the prevalence of gut microbiota dysbiosis [48] and also affects the virulence and growth of bacterial pathogens in microbial infections $[49,50]$. Therefore, we hypothesize that statin use may affect the human gut microbiome, and in turn directly or indirectly reduce hepatocarcinogenesis via the gut-liver axis. Further animal experiments are required to delineate the effects of statins on the development and recurrence of HCC through the gut-microbiota-liver axis. 
Table 3 Multivariate analysis of overall survival after curative hepatectomy for patients with BCLC O/A stage HCC

\begin{tabular}{|c|c|c|c|c|c|c|c|}
\hline \multirow[t]{2}{*}{ Variable } & \multirow[t]{2}{*}{ Comparison } & \multicolumn{2}{|l|}{ All $(n=820)$} & \multicolumn{2}{|l|}{$\mathrm{CHB}(n=458)$} & \multicolumn{2}{|l|}{$\mathrm{CHC}(n=284)$} \\
\hline & & HR $(95 \% \mathrm{Cl})$ & $P$-value & HR $(95 \% \mathrm{Cl})$ & $P$-value & HR $(95 \% \mathrm{Cl})$ & $P$-value \\
\hline Age (years) & $>60$ vs. $\leqq 60$ & & & & & & \\
\hline Sex & Male vs. Female & & & & & & \\
\hline $\operatorname{AFP}(\mathrm{ng} / \mathrm{mL})$ & $>200$ vs. $\leqq 200$ & & & & & & \\
\hline Liver cirrhosis & Yes vs. No & 1.644 (1.180-2.290) & 0.003 & & & $1.828(1.085-3.079)$ & 0.023 \\
\hline Diabetes & Yes vs. No & $2.064(1.478-2.881)$ & $<0.001$ & $2.633(1.611-4.303)$ & $<0.001$ & $1.940(1.166-3.227)$ & 0.011 \\
\hline Child-Pugh grade & B vs. A & 1.915 (1.185-3.096) & 0.008 & $2.223(1.051-4.702)$ & 0.037 & & \\
\hline Tumor number & Multiple vs. Single & & & & & & \\
\hline Tumor size (cm) & $>2$ vs. $\leqq 2$ & & & & & & \\
\hline Histology stages & Poor vs. well + moderate & & & & & & \\
\hline Vascular invasion & Yes vs. No & $2.339(1.670-3.276)$ & $<0.001$ & $2.283(1.403-3.716)$ & 0.001 & $3.068(1.808-5.206)$ & $<0.001$ \\
\hline Statin & Yes vs. No & & & & & & \\
\hline NSAIDs & Yes vs. No & & & & & & \\
\hline Aspirin & Yes vs. No & & & & & & \\
\hline Metformin & Yes vs. No & & & & & & \\
\hline Antiviral therapy & Yes vs. No & $0.350(0.241-0.509)$ & $<0.001$ & & & & \\
\hline NA therapy & Yes vs. No & & & $0.452(0.277-0.740)$ & 0.002 & & \\
\hline HCV therapy & Yes vs. No & & & & & $0.239(0.129-0.445)$ & $<0.001$ \\
\hline
\end{tabular}

NSAIDs Nonsteroidal anti-inflammatory drugs, NA therapy Nucleos(t)ide analogues

HCV therapy included interferon and direct-acting antiviral medications

Table 4 Patient Characteristics in the Propensity Model

\begin{tabular}{|c|c|c|c|c|}
\hline Variable & Statin $(n=46)$ & Non-statin $(n=174)$ & $P$-value & SMD \\
\hline Age, years; mean (SD) & $62.02(8.14)$ & $62.38(9.35)$ & 0.957 & 0.041 \\
\hline Sex & & & 0.975 & 0.005 \\
\hline Male & $40(87.0 \%)$ & $151(86.8 \%)$ & & \\
\hline Female & $6(13.0 \%)$ & $23(13.2 \%)$ & & \\
\hline Diabetes & $27(58.7 \%)$ & $94(54.0 \%)$ & 0.572 & 0.094 \\
\hline HBV & $22(47.8 \%)$ & $78(44.8 \%)$ & 0.717 & 0.059 \\
\hline $\mathrm{HCV}$ & $14(30.4 \%)$ & $56(32.2 \%)$ & 0.821 & 0.037 \\
\hline Liver cirrhosis & $12(26.1 \%)$ & $51(29.3 \%)$ & 0.668 & 0.072 \\
\hline Child-Pugh grade & & & 0.826 & 0.037 \\
\hline A & $42(91.3 \%)$ & $157(90.2 \%)$ & & \\
\hline B & $4(8.7 \%)$ & $17(9.8 \%)$ & & \\
\hline Tumor size $(>2 \mathrm{~cm})$ & 42 (91.3\%) & 162 (93.1\%) & 0.677 & 0.067 \\
\hline Tumor number & & & 0.449 & 0.114 \\
\hline Single & 44 (95.7\%) & $170(97.7 \%)$ & & \\
\hline Multiple & $2(4.3 \%)$ & $4(2.3 \%)$ & & \\
\hline Vascular invasion & $22(47.8 \%)$ & 77 (44.3\%) & & 0.071 \\
\hline
\end{tabular}




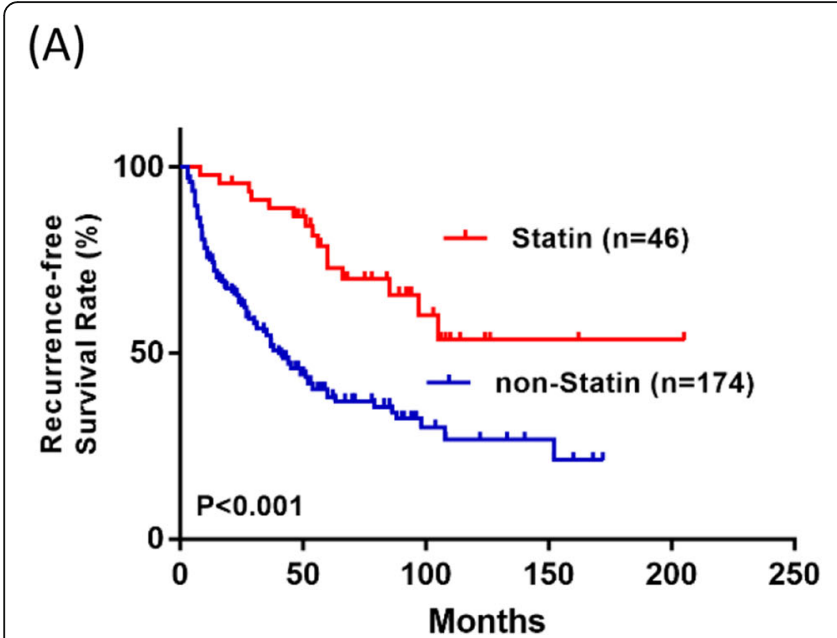

(B)

Fig. 5 Kaplan-Meier cumulative recurrence-free survival a and overall survival b curves for propensity score-matched patients stratified by statin use

There are some limitations to this study. First, this was a retrospective study of patients from a single institution and the data were collected from medical records. Despite the use of multivariable analysis and propensity score-matching analysis, not all confounding factors can be completely adjusted for. Secondly, the number of patients was relatively low. There were 46 (5.6\%) patients in the statin group; however, this is comparable to the study in Japan $(31 / 734,4.2 \%)$ and may reflect the realworld situation. Finally, we could not obtain information on tobacco use and alcohol consumption, which may also be risk factors in survival analysis. Ultimately, a large randomized trial of a suitable regimen in wellselected patients treated using standard approaches is required to obtain this important information.

\section{Conclusions}

In summary, statin use may exert a chemopreventive effect on HCC recurrence after curative resection. Further prospective randomized controlled studies are needed to confirm these observations.

Table 5 Univariate and multivariate analysis for recurrence after curative hepatectomy for propensity score-matched patients with BCLC 0/A stage HCC

\begin{tabular}{|c|c|c|c|c|c|}
\hline \multirow[t]{2}{*}{ Variable } & \multirow[t]{2}{*}{ Comparison } & \multicolumn{2}{|l|}{ Univariate } & \multicolumn{2}{|l|}{ Multivariate } \\
\hline & & $\mathrm{HR}(95 \% \mathrm{Cl})$ & $P$ value & $\mathrm{HR}(95 \% \mathrm{Cl})$ & $P$-value \\
\hline Age (years) & $>60$ vs. $\leqq 60$ & $1.013(0.696-1.473)$ & 0.947 & & \\
\hline Sex & Male vs. Female & $0.933(0.557-1.561)$ & 0.791 & & \\
\hline AFP (ng/mL) & $>200$ vs. $\leqq 200$ & $0.785(0.456-1.351)$ & 0.381 & & \\
\hline Liver cirrhosis & Yes vs. No & $1.436(0.982-2.102)$ & 0.062 & & \\
\hline Diabetes & Yes vs. No & $1.733(1.194-2.517)$ & 0.004 & $1.807(1.241-2.632)$ & 0.002 \\
\hline Child-Pugh grade & B vs. A & $1.345(0.756-2.395)$ & 0.313 & & \\
\hline Tumor number & Multiple vs. Single & $1.374(0.506-3.729)$ & 0.533 & & \\
\hline Tumor size $(\mathrm{cm})$ & $>2$ vs. $\leqq 2$ & $1.854(0.819-4.243)$ & 0.138 & & \\
\hline Histology stages & poor vs. well + moderate & $1.143(0.652-2.004)$ & 0.640 & & \\
\hline Vascular invasion & Yes vs. No & $1.511(1.046-2.184)$ & 0.028 & 1.446 (0.999-2.093) & 0.051 \\
\hline Statin & Yes vs. No & $0.328(0.190-0.566)$ & $<0.001$ & $0.304(0.176-0.525)$ & $<0.001$ \\
\hline NSAID & Yes vs. No & 1.379 (0.606-3.318) & 0.443 & & \\
\hline Aspirin & Yes vs. No & $0.689(0.401-1.184)$ & 0.178 & & \\
\hline Metformin & Yes vs. No & $0.811(0.508-1.296)$ & 0.381 & & \\
\hline NA therapy & Yes vs. No & $0.670(0.424-1.057)$ & 0.085 & & \\
\hline HCV therapy & Yes vs. No & $0.963(0.568-1.634)$ & 0.890 & & \\
\hline
\end{tabular}


Table 6 Univariate and multivariate analysis for overall survival after curative hepatectomy for propensity score-matched patients with BCLC O/A stage HCC

\begin{tabular}{|c|c|c|c|c|c|}
\hline \multirow[t]{2}{*}{ Variable } & \multirow[t]{2}{*}{ Comparison } & \multicolumn{2}{|l|}{ Univariate } & \multicolumn{2}{|l|}{ Multivariate } \\
\hline & & HR (95\% Cl) & $P$-value & HR $(95 \% \mathrm{Cl})$ & $P$-value \\
\hline Age (years) & $>60$ vs. $\leqq 60$ & $0.990(0.558-1.757)$ & 0.974 & & \\
\hline Sex & Male vs. Female & $1.013(0.455-2.253)$ & 0.975 & & \\
\hline $\operatorname{AFP}(n g / m L)$ & $>200$ vs. $\leqq 200$ & $1.172(0.545-2.518)$ & 0.685 & & \\
\hline Liver cirrhosis & Yes vs. No & 1.669 (0.942-2.955) & 0.079 & & \\
\hline Diabetes & Yes vs. No & 3.175 (1.652-6.103) & 0.001 & $2.942(1.514-5.717)$ & 0.001 \\
\hline Child-Pugh grade & B vs. A & $1.415(0.601-3.330)$ & 0.427 & & \\
\hline Tumor number & Multiple vs. Single & $0.711(0.098-5.159)$ & 0.736 & & \\
\hline Tumor size (cm) & $>2$ vs. $\leqq 2$ & $4.271(0.588-30.998)$ & 0.151 & & \\
\hline Histology stages & poor vs. well + moderate & $1.651(0.651-4.187)$ & 0.291 & & \\
\hline Vascular invasion & Yes vs. No & $2.455(1.367-4.409)$ & 0.003 & 1.979 (1.092-3.588) & 0.025 \\
\hline Statin & Yes vs. No & $0.509(0.229-1.132)$ & 0.098 & & \\
\hline NSAID & Yes vs. No & 3.305 (1.309-8.345) & 0.011 & $3.343(1.303-8.580)$ & 0.012 \\
\hline Aspirin & Yes vs. No & $1.021(0.479-2.176)$ & 0.957 & & \\
\hline Metformin & Yes vs. No & $1.310(0.669-2.566)$ & 0.431 & & \\
\hline NA therapy & Yes vs. No & $0.830(0.425-1.622)$ & 0.586 & & \\
\hline HCV therapy & Yes vs. No & $0.440(0.137-1.418)$ & 0.169 & & \\
\hline
\end{tabular}

\section{Supplementary Information}

The online version contains supplementary material available at https://doi. org/10.1186/s12885-021-07796-7.

Additional file 1: Supplementary Figure 1. Kaplan-Meier cumulative recurrence-free survival curves for patients with HCC using statins stratified by (A) lipophilic or hydrophilic statins and (B) individual statins.

Additional file 2: Supplementary Figure 2. Kaplan-Meier (A) liverrelated survival and (B) non-liver-related survival curves after curative resection for patients with HCC stratified by statin use.

\section{Abbreviations}

HCC: Hepatocellular carcinoma; BCLC: Barcelona Clinic Liver Cancer; OS: Overall survival; RFS: Recurrence-free survival; HR: Hazard ratio; HBV: Hepatitis B virus; HCV: Hepatitis C virus; RFA: Radiofrequency ablation; NA: Nucleos(t)ide analogue; HMG-CoA: 3-hydroxy-3-methyglutaryl-coenzyme A; DDD: Defined daily dose; AFP: Alpha-fetoprotein; HBsAg: Hepatitis B surface antigen; HCVAb: Hepatitis C virus antibody; CDK: Cyclin-dependent kinase; SMD: Standardized mean difference; NSAIDs: Nonsteroidal antiinflammatory drugs

\section{Acknowledgments}

This study was supported by grants CMRPG8L0261 from Chang Gung Memorial Hospital, Taiwan. The authors would like to thank all of the patients and their providers who participated in this study. We also thank the Biostatistics Center, Kaohsiung Chang Gung Memorial Hospital, for statistical work.

\section{Authors' contributions}

Conceptualization, K.-D.C. and M.-C.T.; Data curation, C.-C.W., Y.-W.L., C.-C.L., Y.-C.T., C.-C.Y., Y.-H.Y. and T.-H.H.; Methodology, C.-H.C.; Supervision, M.-C.T and C.-C.H.; Writing —original draft, S.-Y.Y.; Writing—review \& editing, M.-C.T and C.-C.H. All authors have read and approved the final manuscript.

\section{Funding}

This research received no specific grant from any funding agency in the public, commercial, or not-for-profit sectors.

\section{Availability of data and materials}

The original data are available upon reasonable request to the corresponding author.

\section{Ethics approval and consent to participate}

The clinical data was acquired with the approval and permission of the Institutional Review Board of the Kaohsiung Chang Gung Memorial Hospital. The study protocol was approved by the Institutional Review Board of the Kaohsiung Chang Gung Memorial Hospital. Informed consent was not required because this study was a retrospective report of cases, which is a retrospective analysis of clinical data with no relevant to human biological ethic problems.

\section{Consent for publication}

Not applicable.

\section{Competing interests}

The authors have no competing interests to declare.

\section{Author details}

'Division of Hepato-Gastroenterology, Department of Internal Medicine, Kaohsiung Chang Gung Memorial Hospital and Chang Gung University College of Medicine, 123 Ta Pei Road, Kaohsiung, Taiwan. ${ }^{2}$ Liver Transplantation Center and Department of Surgery, Kaohsiung Chang Gung Memorial Hospital and Chang Gung University College of Medicine, Kaohsiung, Taiwan. ${ }^{3}$ Center for Translational Research in Biomedical Sciences, Liver Transplantation Program and Department of Surgery, Kaohsiung Chang Gung Memorial Hospital and Chang Gung University College of Medicine, Kaohsiung, Taiwan. ${ }^{4}$ Head Nurse, Department of Nursing, Kaohsiung Chang Gung Memorial Hospital, Kaohsiung, Taiwan. ${ }^{5}$ Graduate Institute of Clinical Medical Sciences, College of Medicine, Chang Gung University, Taoyuan, Taiwan. ${ }^{6}$ Division of Pulmonary and Critical Care Medicine, Department of 
Medicine, Kaohsiung Chang Gung Memorial Hospital and Chang Gung University College of Medicine, Kaohsiung, Taiwan.

\section{Received: 14 October 2020 Accepted: 6 January 2021} Published online: 15 January 2021

\section{References}

1. Bray F, Ferlay J, Soerjomataram I, Siegel RL, Torre LA, Jemal A. Global cancer statistics 2018: GLOBOCAN estimates of incidence and mortality worldwide for 36 cancers in 185 countries. CA Cancer J Clin. 2018;68(6):394-424.

2. Llovet JM, Zucman-Rossi J, Pikarsky E, Sangro B, Schwartz M, Sherman M, Gores G. Hepatocellular carcinoma. Nat Rev Dis Primers. 2016;2:16018.

3. Yang JD, Hainaut P, Gores GJ, Amadou A, Plymoth A, Roberts LR. A global view of hepatocellular carcinoma: trends, risk, prevention and management. Nat Rev Gastroenterol Hepatol. 2019;16(10):589-604.

4. Omata M, Cheng AL, Kokudo N, Kudo M, Lee JM, Jia J, Tateishi R, Han KH, Chawla YK, Shiina S, et al. Asia-Pacific clinical practice guidelines on the management of hepatocellular carcinoma: a 2017 update. Hepatol Int. 2017; 11(4):317-70.

5. Heimbach JK, Kulik LM, Finn RS, Sirlin CB, Abecassis MM, Roberts $L R$, Zhu AX, Murad MH, Marrero JA. AASLD guidelines for the treatment of hepatocellular carcinoma. Hepatology. 2018;67(1):358-80.

6. Roayaie S, Jibara G, Tabrizian P, Park JW, Yang J, Yan L, Schwartz M, Han G, Izzo F, Chen M, et al. The role of hepatic resection in the treatment of hepatocellular cancer. Hepatology. 2015;62(2):440-51.

7. Tabrizian P, Jibara G, Shrager B, Schwartz M, Roayaie S. Recurrence of hepatocellular cancer after resection: patterns, treatments, and prognosis. Ann Surg. 2015;261(5):947-55.

8. Ercolani G, Grazi GL, Ravaioli M, Del Gaudio M, Gardini A, Cescon M, Varotti G, Cetta F, Cavallari A. Liver resection for hepatocellular carcinoma on cirrhosis: univariate and multivariate analysis of risk factors for intrahepatic recurrence. Ann Surg. 2003;237(4):536-43.

9. Forner A, Llovet JM, Bruix J. Hepatocellular carcinoma. Lancet. 2012; 379(9822):1245-55.

10. Huang YH, Wu JC, Chen CH, Chang TT, Lee PC, Chau GY, Lui WY, Chang FY, Lee SD. Comparison of recurrence after hepatic resection in patients with hepatitis B vs. hepatitis C-related small hepatocellular carcinoma in hepatitis B virus endemic area. Liver Int. 2005;25(2):236-41.

11. Wu JC, Huang YH, Chau GY, Su CW, Lai CR, Lee PC, Huo TI, Sheen IJ, Lee SD, Lui WY. Risk factors for early and late recurrence in hepatitis B-related hepatocellular carcinoma. J Hepatol. 2009:51 (5):890-7.

12. Hirokawa F, Hayashi M, Asakuma M, Shimizu T, Inoue Y, Uchiyama K. Risk factors and patterns of early recurrence after curative hepatectomy for hepatocellular carcinoma. Surg Oncol. 2016;25(1):24-9.

13. Zheng J, Kuk D, Gonen M, Balachandran VP, Kingham TP, Allen PJ, D'Angelica MI, Jarnagin WR, DeMatteo RP. Actual 10-year survivors after resection of hepatocellular carcinoma. Ann Surg Oncol. 2017;24(5):1358-66.

14. Wu CY, Chen YJ, Ho HJ, Hsu YC, Kuo KN, Wu MS, Lin JT. Association between nucleoside analogues and risk of hepatitis B virus-related hepatocellular carcinoma recurrence following liver resection. JAMA. 2012; 308(18):1906-14

15. Bruix J, Takayama T, Mazzaferro V, Chau GY, Yang J, Kudo M, Cai J, Poon RT, Han KH, Tak WY, et al. Adjuvant sorafenib for hepatocellular carcinoma after resection or ablation (STORM): a phase 3, randomised, double-blind, placebo-controlled trial. Lancet Oncol. 2015;16(13):1344-54.

16. Cholesterol Treatment Trialists C, Baigent C, Blackwell L, Emberson J, Holland LE, Reith C, Bhala N, Peto R, Barnes EH, Keech A, et al. Efficacy and safety of more intensive lowering of LDL cholesterol: a meta-analysis of data from 170,000 participants in 26 randomised trials. Lancet. 2010; 376(9753):1670-81.

17. Tsan YT, Lee CH, Wang JD, Chen PC. Statins and the risk of hepatocellular carcinoma in patients with hepatitis B virus infection. J Clin Oncol. 2012; 30(6):623-30.

18. Hsiang JC, Wong GL, Tse YK, Wong WW, Yip TC, Chan HL. Statin and the risk of hepatocellular carcinoma and death in a hospital-based hepatitis Binfected population: a propensity score landmark analysis. J Hepatol. 2015; 63(5):1190-7.

19. Tsan YT, Lee CH, Ho WC, Lin MH, Wang JD, Chen PC. Statins and the risk of hepatocellular carcinoma in patients with hepatitis C virus infection. J Clin Oncol. 2013;31(12):1514-21.
20. Butt AA, Yan P, Bonilla H, Abou-Samra AB, Shaikh OS, Simon TG, Chung RT, Rogal SS, Team ES. Effect of addition of statins to antiviral therapy in hepatitis C virus-infected persons: results from ERCHIVES. Hepatology. 2015; 62(2):365-74.

21. Demierre MF, Higgins PD, Gruber SB, Hawk E, Lippman SM. Statins and cancer prevention. Nat Rev Cancer. 2005;5(12):930-42.

22. Urbich C, Dernbach E, Zeiher AM, Dimmeler S. Double-edged role of statins in angiogenesis signaling. Circ Res. 2002;90(6):737-44.

23. Villanueva A. Hepatocellular Carcinoma. N Engl J Med. 2019;380(15):1450-62.

24. WHO. Collaborating Centre for Drug Statistics Methodology, Guidelines for ATC classification and DDD assignment 2020. Oslo; 2019. https://www. whocc.no/filearchive/publications/2020_guidelines_web.pdf

25. Llovet JM, Bru C, Bruix J. Prognosis of hepatocellular carcinoma: the BCLC staging classification. Semin Liver Dis. 1999;19(3):329-38.

26. Asselah T, Marcellin P, Bedossa P. Improving performance of liver biopsy in fibrosis assessment. J Hepatol. 2014;61(2):193-5.

27. Fujiwara N, Friedman SL, Goossens N, Hoshida Y. Risk factors and prevention of hepatocellular carcinoma in the era of precision medicine. J Hepatol. 2018;68(3):526-49.

28. Singh $S$, Singh PP, Roberts $L R$, Sanchez W. Chemopreventive strategies in hepatocellular carcinoma. Nat Rev Gastroenterol Hepatol. 2014;11(1):45-54.

29. Blaha MJ, Martin SS. How do statins work?: changing paradigms with implications for statin allocation. J Am Coll Cardiol. 2013;62(25):2392-4.

30. Kim G, Jang SY, Han E, Lee YH, Park SY, Nam CM, Kang ES. Effect of statin on hepatocellular carcinoma in patients with type 2 diabetes: a nationwide nested case-control study. Int J Cancer. 2017;140(4):798-806.

31. Facciorusso A, Abd El Aziz MA, Singh S, Pusceddu S, Milione M, Giacomelli L, Sacco R. Statin Use Decreases the Incidence of Hepatocellular Carcinoma: An Updated Meta-Analysis. Cancers (Basel). 2020;12(4):874.

32. Kawaguchi Y, Sakamoto Y, Ito D, Ito K, Arita J, Akamatsu N, Kaneko J, Hasegawa K, Moriya K, Kokudo N. Statin use is associated with a reduced risk of hepatocellular carcinoma recurrence after initial liver resection. Biosci Trends. 2017;11(5):574-80.

33. Gazzerro P, Proto MC, Gangemi G, Malfitano AM, Ciaglia E, Pisanti S, Santoro A, Laezza C, Bifulco M. Pharmacological actions of statins: a critical appraisal in the management of cancer. Pharmacol Rev. 2012;64(1):102-46.

34. Wong WW, Dimitroulakos J, Minden MD, Penn LZ. HMG-CoA reductase inhibitors and the malignant cell: the statin family of drugs as triggers of tumor-specific apoptosis. Leukemia. 2002;16(4):508-19.

35. Rao S, Porter DC, Chen X, Herliczek T, Lowe M, Keyomarsi K. Lovastatinmediated G1 arrest is through inhibition of the proteasome, independent of hydroxymethyl glutaryl-CoA reductase. Proc Natl Acad Sci U S A. 1999; 96(14):7797-802.

36. Shibata MA, Kavanaugh C, Shibata E, Abe H, Nguyen P, Otsuki Y, Trepel JB, Green JE. Comparative effects of lovastatin on mammary and prostate oncogenesis in transgenic mouse models. Carcinogenesis. 2003;24(3):453-9.

37. Dulak J, Jozkowicz A. Anti-angiogenic and anti-inflammatory effects of statins: relevance to anti-cancer therapy. Curr Cancer Drug Targets. 2005; 5(8):579-94.

38. Kwak B, Mulhaupt F, Myit S, Mach F. Statins as a newly recognized type of immunomodulator. Nat Med. 2000;6(12):1399-402.

39. Chong LW, Hsu YC, Lee TF, Lin Y, Chiu YT, Yang KC, Wu JC, Huang YT. Fluvastatin attenuates hepatic steatosis-induced fibrogenesis in rats through inhibiting paracrine effect of hepatocyte on hepatic stellate cells. BMC Gastroenterol. 2015;15:22.

40. Hoshida Y, Fuchs BC, Tanabe KK. Prevention of hepatocellular carcinoma: potential targets, experimental models, and clinical challenges. Curr Cancer Drug Targets. 2012;12(9):1129-59.

41. Yang PM, Liu YL, Lin YC, Shun CT, Wu MS, Chen CC. Inhibition of autophagy enhances anticancer effects of atorvastatin in digestive malignancies. Cancer Res. 2010;70(19):7699-709.

42. McKenney JM. Pharmacologic characteristics of statins. Clin Cardiol. 2003; 26(4 Suppl 3):III32-8.

43. Young SH, Chau GY, Lee IC, Yeh YC, Chao Y, Huo TI, Su CW, Lin HC, Hou $M C$, Lee $\mathrm{MH}$, et al. Aspirin is associated with low recurrent risk in hepatitis $B$ virus-related hepatocellular carcinoma patients after curative resection. J Formos Med Assoc. 2020;119(1 Pt 2):218-29.

44. Simon TG, Duberg AS, Aleman S, Chung RT, Chan AT, Ludvigsson JF. Association of Aspirin with hepatocellular carcinoma and liver-related mortality. N Engl J Med. 2020;382(11):1018-28. 
45. Choi Y, Choi Y, Choi CS, Lee YH. Diabetes mellitus increases the risk of intrahepatic recurrence of hepatocellular carcinoma after surgical resection. Tumori. 2017;103(3):279-85.

46. Fukui H. Role of Gut Dysbiosis in Liver Diseases: What Have We Learned So Far? Diseases. 2019;7(4):58.

47. Chu H, Duan Y, Yang L, Schnabl B. Small metabolites, possible big changes: a microbiota-centered view of non-alcoholic fatty liver disease. Gut. 2019; 68(2):359-70.

48. Vieira-Silva S, Falony G, Belda E, Nielsen T, Aron-Wisnewsky J, Chakaroun R, Forslund SK, Assmann K, Valles-Colomer M, Nguyen TTD, et al. Statin therapy is associated with lower prevalence of gut microbiota dysbiosis. Nature. 2020;581(7808):310-5.

49. Hennessy E, Adams C, Reen FJ, O'Gara F. Is there potential for repurposing statins as novel antimicrobials? Antimicrob Agents Chemother. 2016;60(9): 5111-21.

50. Smit J, Lopez-Cortes LE, Thomsen RW, Schonheyder HC, Nielsen H, Froslev T, Rodriguez-Bano J, Sogaard M. Statin use and risk of community-acquired Staphylococcus aureus bacteremia: a population-based case-control study. Mayo Clin Proc. 2017;92(10):1469-78.

\section{Publisher's Note}

Springer Nature remains neutral with regard to jurisdictional claims in published maps and institutional affiliations.

Ready to submit your research? Choose BMC and benefit from:

- fast, convenient online submission

- thorough peer review by experienced researchers in your field

- rapid publication on acceptance

- support for research data, including large and complex data types

- gold Open Access which fosters wider collaboration and increased citations

- maximum visibility for your research: over $100 \mathrm{M}$ website views per year

At BMC, research is always in progress.

Learn more biomedcentral.com/submissions 